\title{
The endurance test: A virtual project team's lived experience in an online project management course
}

\author{
Michael F. Lohle, University of Bridgeport, mlohle@bridgeport.edu \\ Steven Terrell, Nova Southeastern University, terrell@nova.edu
}

\begin{abstract}
This case study examines longitudinal data stored in the learning management system (LMS) of an online MBA program's project management course to understand and describe the lived experience of a virtual student team that exhibited difficulty delivering a term project. Testing the constructs of a theoretical model previously proposed in literature, the findings consider whether the model design can be applied in a specific situation and suggests additional case studies are warranted for further understanding. The findings also confirmed two concerns. First, unless students actively contact their instructor to escalate feedback about progress, it is difficult to assess a given student's contribution to virtual team projects. Second, the instructor actively solicited feedback and facilitated closure to compensate for a lack of student accountability, prompting concern about whether requiring an online instructor's constant oversight and engagement is an optimal strategy for effective project delivery on virtual student teams.
\end{abstract}

Keywords: online pedagogy, virtual teams, project management, learning management system, LMS, troubled projects, knowledge management, grounded theory, theoretical sampling

\section{Introduction}

This case study builds upon findings by Lohle and Terrell (2016) where feedback from online students who engaged in virtual team projects was used to generate a grounded theory to help online instructors facilitate such projects. Leveraging discussions captured in the learning management system (LMS) at a small university in the northeastern United States, the researchers analyzed feedback from 34 students taking a project management course, over three semesters, in an online MBA program. Students were assigned to self-managed work teams in delivering a research paper and asked to discuss their experiences while coming together over the first three weeks of this eight week course, at the completion of their projects' initiation phase. Their feedback was used to generate the theoretical model found in Figure 1. The theoretical model in Figure 1 depicts one dependent variable, effective virtual team project delivery. Communication, the student's most cited concern, bounds the model because for virtual teams to successfully deliver projects, active and effective communication is a fundamental requirement. Then, student accountability and scheduling comprise the model's two independent variables while the remaining feedback was clustered into two moderating variables, "critical success factors" and "coaching points." 


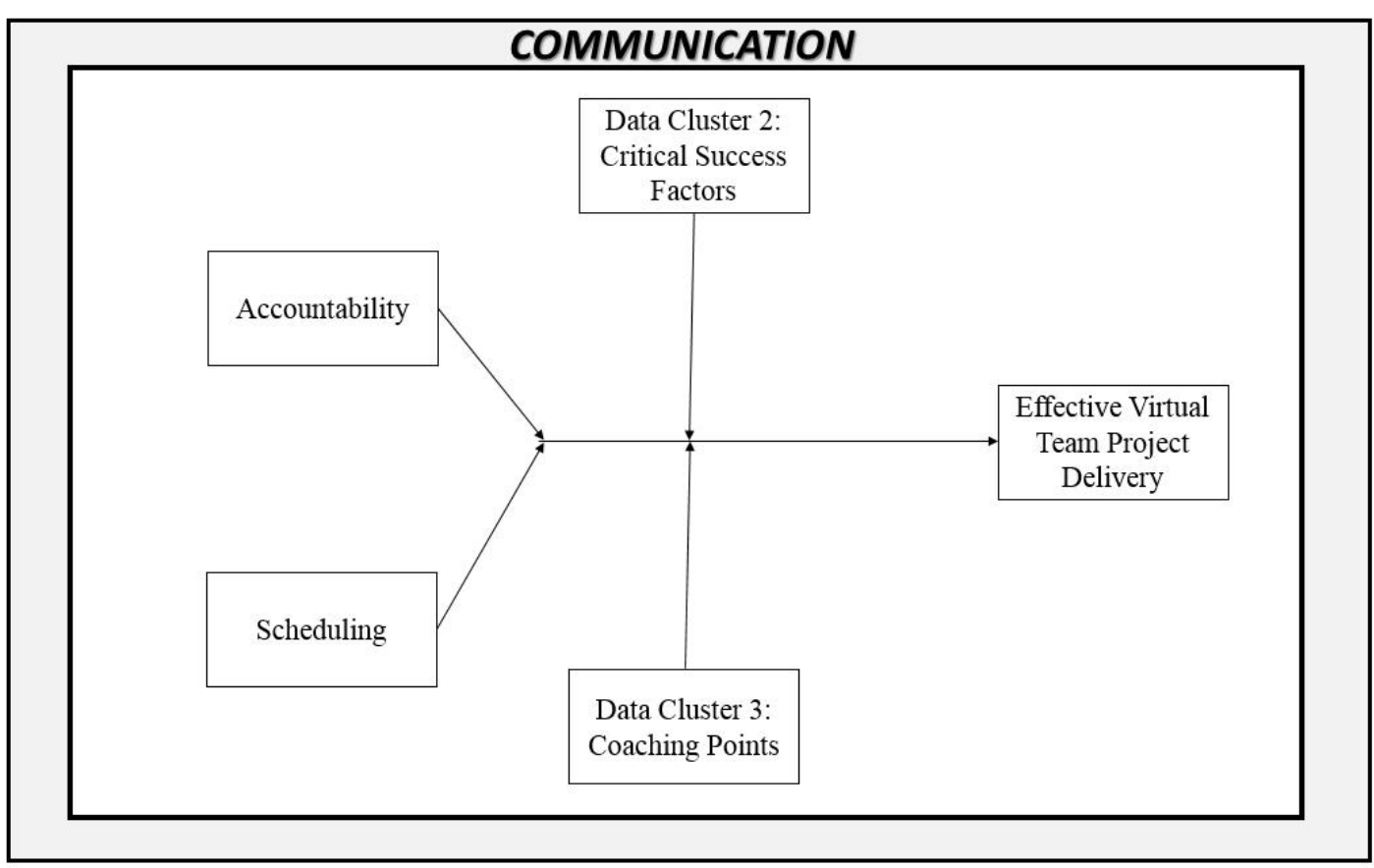

Figure 1. A Grounded Theoretical Model for Student Project Delivery on Virtual Teams.

\section{Methodology}

The purpose of this case study was to test the theoretical model Lohle and Terrell (2016) proposed in their earlier study by examining longitudinal data about the lived experience of a single student project team captured during one project management course in one eight-week semester. While the previous study focused exclusively on public discussion threads, this case study focused on data from three electronic communications media:

- Status reports

- Personal reflections constituting a one-on-one dialog between students and the instructor

- E-mail communications.

Per Creswell (2007) as well as Glaser and Strauss (1967), communications were analyzed and margin notes documented. This case summary was generated from these notes. As Eisenhardt (1989) suggested, this case study was chosen to test the constructs of Lohle and Terrell (2016)'s theoretical model for validity to ensure it constitutes "good theory." Such cases are similar to experiments where obtaining an in-depth understanding is akin to achieving successful experimental results, however the findings may also suggest additional avenues of inquiry.

\section{The LMS as a Knowledge Base}

Davenport (2015) and Skyrme (2011) have both asserted knowledge management is no longer a viable field of study. This paper's authors disagree. Instead, their use of this knowledge base's experiential data to draw conclusions supported Lee's (2015) assertion that knowledge management is no longer an isolated function, instead it has become a capability integrated into 
the fabric of business. Moreover, the analysis process employed resembled Nonaka's (1994) Knowledge Creation Theory that depicts a "spiral" where explicit knowledge is continually transformed into tacit knowledge and back again. In the previous case explicit student feedback was transformed into tacit knowledge via Lohle and Terrell's (2016) grounded theory. This case study continued Nonaka's (1994) knowledge creation spiral using the iterative process suggested by Eisenhardt (1989) where in-depth case study analysis was applied to test the construct validity of their theoretical model.

\section{Theoretical Sampling}

The course LMS contains extensive longitudinal data covering multiple team projects over several semesters. Per Eisenhardt (1989), theoretical sampling was conducted to select a specific case to confirm the construct validity of Lohle and Terrell's (2016) theoretical model. The experience of one team that exhibited difficulty with delivering their research paper during one semester was chosen because this team escalated more frequently than the others, required the most instructor intervention and was the only team that agreed to adjust their final project grade according to their contribution. This team consisted of three students, referenced here as Student A, Student B and Student C.

\section{Course Content}

This case study focuses on an assignment to deliver a team term paper comprising fifteen percent of students' overall grade in an online project management course. Self-managed student teams were assigned and weekly assignments followed this schedule:

- Week 1: Teams submitted one paragraph confirming how they would communicate and hold underperforming peers accountable. In the communication tallies depicted later, this document is included in the counts of weekly status reports.

- Week 2: Teams submitted one paragraph describing the content and title of their proposed term paper and the division of labor. In the communication tallies depicted later, this document is also included in the counts of weekly status reports.

- Weeks 3-7: Teams submitted weekly status reports covering progress to date, risks and notes.

- Week 8: Teams submitted their final research papers.

The course design provided ample opportunities for student engagement:

- Four synchronous meetings were held every two weeks.

- Video feedback was sent to each team for all assignments.

- Written comments were provided for each submission via the LMS' inline comments feature.

- Video and written feedback was provided for students' personal reflections.

- The instructor responded to e-mails received within twelve hours.

While the instructor engaged students using these communication tools, the instructor did not review interim research paper drafts during the semester, instead the final paper was received and reviewed at the end of the semester. 
Students were graded individually to account for variations in contribution. Peer reviews were not established so the instructor concluded that, unless students escalated concerns, the teams were harmonious. The instructor also conveyed these points to the class:

- Teams that do not address communication issues will not deliver effectively.

- The weekly status report should be used to describe the impact of underperforming teammates.

- Teams should invite the instructor to join team meetings if additional support is required.

\section{Findings}

The following occurred during the eight weeks between March 28 and May 21, 2016.

\section{March 28}

The team confirmed they would use Google applications for communicating and meet weekly via videoconference. If procrastination or under performance was observed an e-mail copying all team members would be sent to the instructor. After an initial warning the offending team member's grade would be reduced by 10 points for the impacted assignment.

\section{April 4}

The team divided their responsibilities and confirmed their research paper would focus on establishing effective teamwork.

\section{April 9}

Student A sent the team an e-mail confirming she would be unavailable one day while driving to the airport and she would also not be available the day after. She confirmed the team had not set a meeting time to justify her absence and asked the others to respond with their availability.

\section{April 10}

Student $\mathrm{C}$ confirmed he had assumed many personal responsibilities in addition to the course and this had adversely impacted his course work. Meanwhile, Student B acknowledged the team experienced issues in drafting and adhering to a schedule but described these as "minor hiccups." This student also mentioned the loss of a team member the previous week without explaining why and confirmed the team pulled together despite this and was excited.

\section{April 11}

Student A questioned her teammates' commitment, expressed discomfort with sharing this and then mentioned possessing e-mail evidence proving their lack of contribution. Student A then asserted she shared this information with the instructor to "avoid spin" and present "her side." 


\section{April 17}

The week's status report established a schedule and emphasized the importance of meetings. In it the team confirmed they were "too relaxed" the previous week, did not confirm meeting times and were confused with required tasks. Student A admitted to being a "control freak" and became exasperated with her inability to exert control over the others. Concerned the course was now half over, Student A continued "I hope we can get a handle on this before the end of the course." In a response to instructor feedback Student A then wrote, "All is well with my group," and confirmed previous escalation to the instructor "shook" teammates "back to reality." The instructor suggested documenting information about under-performing peers in the team's weekly status report. This never occurred.

\section{April 23}

Despite earlier confirmation they would use Google applications for communication the team primarily used e-mail instead until team members reported not receiving important messages. They then transitioned to using Google Hangouts and text messages as originally planned. Student A complained the others were preoccupied during their weekly video conference and remained confused, with Students B and C submitting less than expected. Student A stated she now led the team and the extra effort required adversely impacted her other course deliverables. She blamed her teammates' preoccupation with other priorities for extensive rewrites, chronic delays, continued confusion and low quality. The instructor acknowledged if one student contributed more than the others they should receive a higher grade but also confirmed the team was required to unanimously ratify such a grade allocation. He offered to attend the next team meeting to facilitate progress. The team never accepted his offer.

\section{April 24}

The team's next weekly status report was positive, confirming they delivered all scheduled tasks, team meetings facilitated progress and they planned to meet and review their draft paper during the coming week. Despite this, miscommunication remained a problem and "missing deadlines appears to be a running theme." Student C shared heightened concern about increased responsibilities and workload and implied his school work was suffering.

\section{April 28}

Student A continued to escalate concerns about teammates and confirmed the group was not unified and did not adequately share with each other or reach conclusions during team meetings. She vowed to continue escalation, convinced it triggered a "drastic" change in the team's attitude.

\section{May 1}

An upbeat tone again infused this week's status report. It confirmed team members submitted their research drafts, reconfirmed their task assignments and although conflicts occurred during the week they "pledged total transparency" and vowed to meet their commitments. 


\section{May 7}

Student B's weekly reflection asserted things were "wonderful:" the team was synchronized and engaged in meaningful dialog. Student B also confirmed she attended the school's graduation ceremony the previous weekend and this course was the last requirement before she finished the MBA program.

\section{May 8}

Draft paper reviews and best practice brainstorming were reported in this week's status report and the list of open milestones was reduced, implying positive progress. The report also confirmed one team member needed to travel for work the following week so the team rearranged their meetings to accommodate and confirmed this threatened progress. Despite this, the team affirmed they overcame communication challenges and were back on schedule.

Despite the weekly status report's positive tone Student A told the instructor she decided to miss a deadline to attend a Cinco de Mayo celebration. Itemizing the many ways the other team members disappointed her as justification Student A stated "My team members have broken the rules all semester, so why not?" Meanwhile, Student B discussed an intense meeting where the team addressed chronic difficulty meeting deadlines and effectively communicating, "This week ended well with the team on track and meeting deadlines. It was our best week yet as a team."

Student C reaffirmed his personal commitments had adversely impacted him, "I had little sleep for a few days... This week was a complete mess...All of my classes have suffered as a result." Despite these concerns Student C resolved to finish strong.

\section{May 15}

This week's status report affirmed the team was delivering on schedule and emphasized, "We are extremely proud of our efforts toward effective and frequent communication. Teamwork actually has made the dream work." Simultaneously, Student C added preparing for an overseas trip to his burgeoning list of personal priorities.

Student B remained upbeat, "...my group has been doing extremely well. We've been communicating well and our project is in the completion stage." Having graduated two weeks before, she also mentioned the impact that attending the graduation ceremony had on her motivation, "...when you come this far you become lax and the restlessness of finishing overshadows the goal."

\section{May 19}

Student A complained Student C sent early morning e-mails with incorrect attachments and evident confusion and then confirmed she personally lost track of time the prior week while on a business trip, confused the days of the week and submitted late drafts to teammates. Having 
received Student A's extensive complaints about teammates until then the instructor responded Student A was now part of the problem.

The instructor received an e-mail chain where Student A and Student C argued over grammatical errors and Student B interjected, "Can we just take deep breaths here? We're right there. We're almost done. Let's breathe and be kind to each other." Student A retorted, "I'm not just trying to pass. I would like the paper to reflect an A effort...we all stand to benefit from good work," and chastised the others for not agreeing to review the paper together. The instructor intervened and confirmed nothing motivates like a milestone and the team did not trust each other because they could not rely on each other. He confirmed they now were required to either share their individual contributions with him or he would conclude everyone contributed equally to the final work product and grade the team accordingly.

\section{May 20 - Project Due Date}

On the day the team's research paper was due Student A continued to express concerns and rewrote the research paper's introduction, offending Student C. Student B then submitted work Student A called "atrocious." Another extended dialog ensued.

Once again the instructor intervened, urging the team to include a section in their final paper breaking out each student's contribution:

- Student A: \#\#\%

- Student B: \#\#\%

- Student C: \#\#\%.

He demanded unanimity and explained the paper's grade would be the "ceiling:" the student who contributed the most would achieve that grade while the grades of those who contributed less would be lowered accordingly. The students agreed.

The team recorded this grading distribution based on their relative contribution to their final paper:

- Student A: $40 \%$

- Student B: $30 \%$

- Student C: $30 \%$.

\section{Discussion}

\section{Testing the Theoretical Model's Construct Validity}

Figure 2 displays a horizontal bar chart depicting the number of unique communications by type between the three team members and their instructor throughout their eight-week term project. First, the team was required to submit seven weekly status reports. Then, each team member was required to share seven weekly personal reflections for a total of 21 personal reflections. Finally, 37 e-mails were sent between the team members and instructor. 


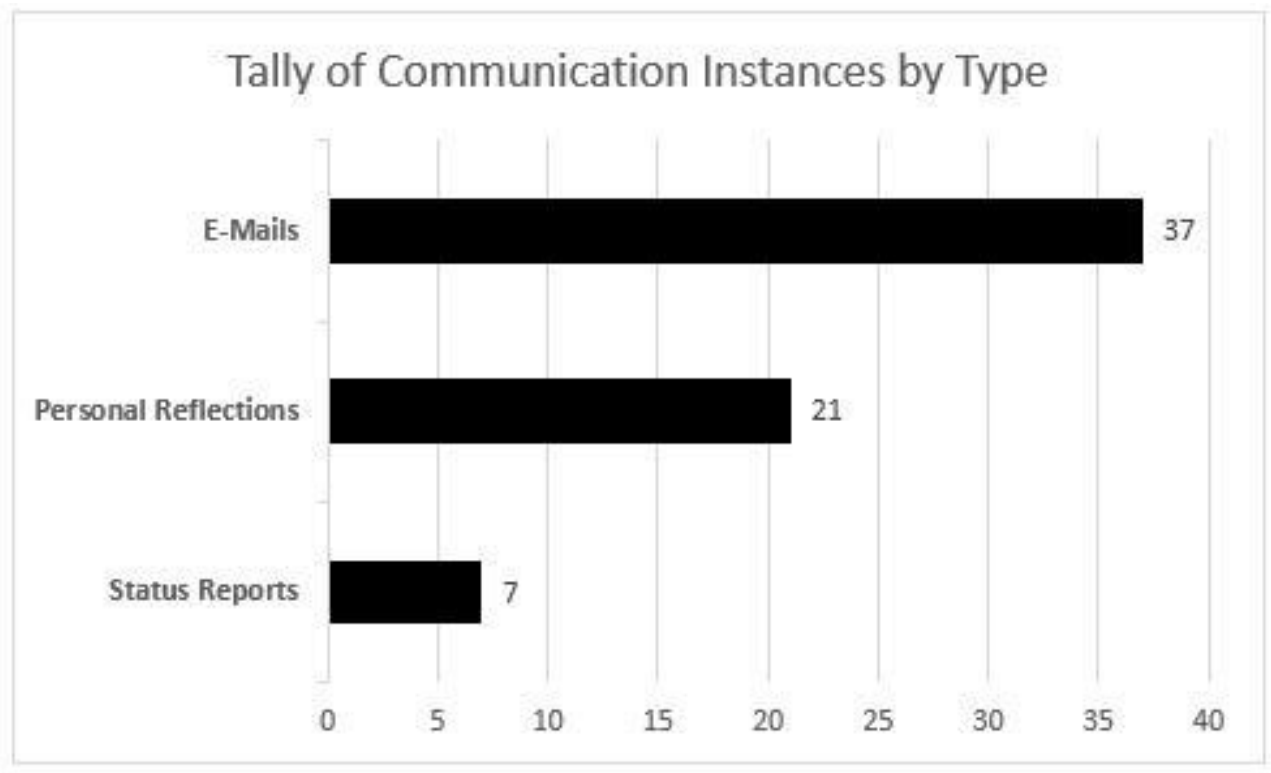

Figure 2. Tally of communication instances by type.

Figure 3 displays a line chart depicting the number of the e-mails sent between the case's team members and their instructor over time during the semester:

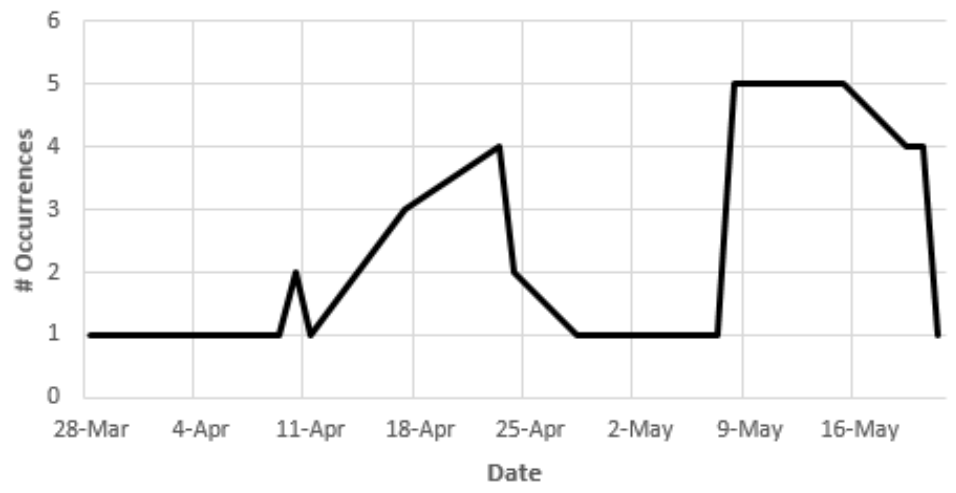

Figure 3. Number of E-Mail Communication Occurrences by Date.

The dramatic increase in communication midway through the project exemplifies Gersick's (1988) research findings that after coming together project teams tend to experience challenges around midpoint and then either decide to succeed and deliver or fail. Considering the subsequent, sustained plateau of heightened communications that occurred between May 9 until May 16 and the reality that during this time the team encountered extreme challenges and required extensive coaching it seems apparent this team never came together and therefore experienced Gersick's worst case scenario.

Since the purpose of this case study was to test the construct validity of Lohle and Terrell's (2016) theoretical model, the count of student references to accountability, communications and schedule 
concerns depicted in Figure 4 is instructive since these variables constitute the model's central phenomenon from their previous study as depicted in Table 1.

Table 1. Qualitative coding analysis from Lohle and Terrell (2016)
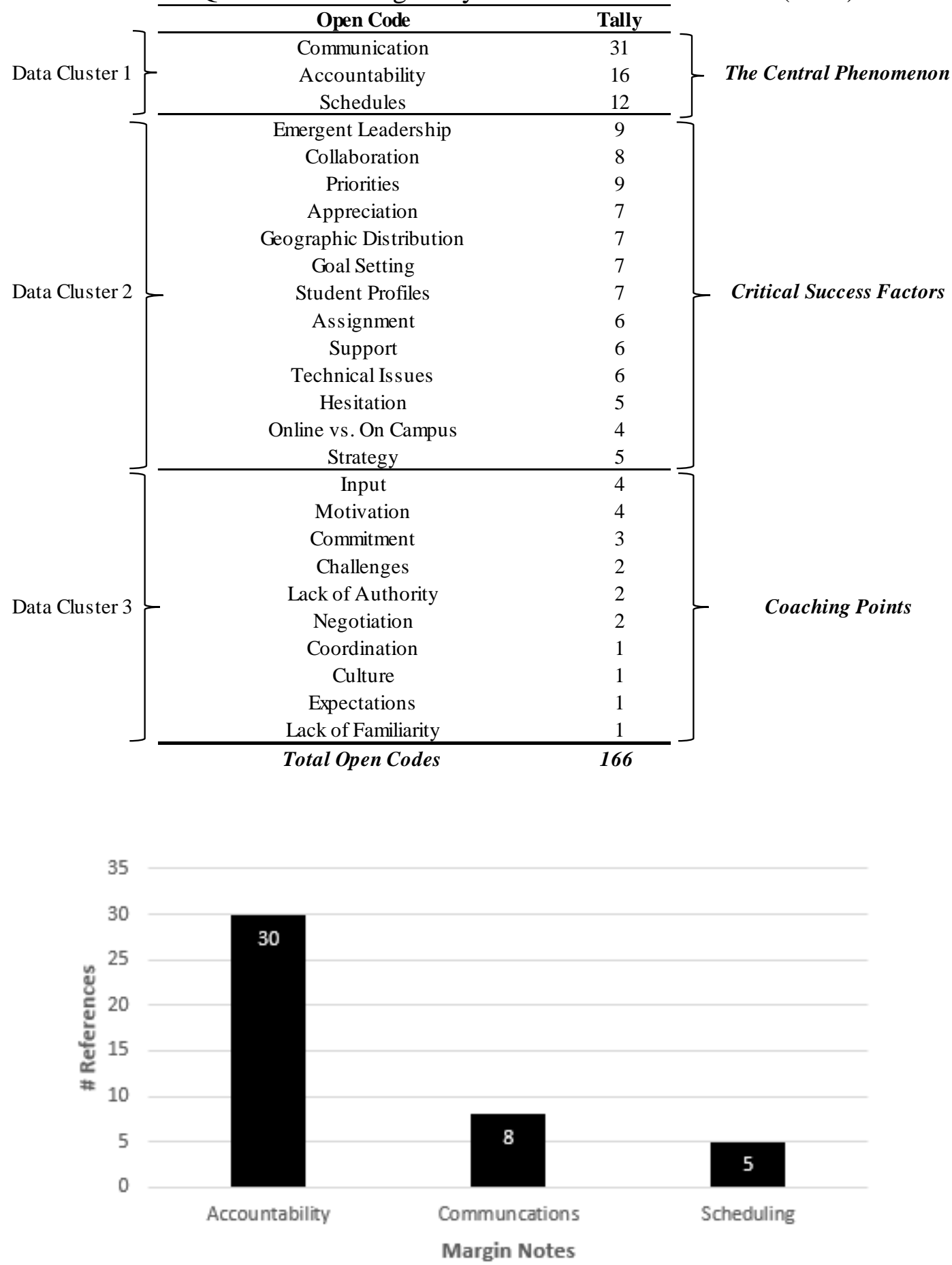

Figure 4. Count of Margin Notes' References to Accountability, Communications and Scheduling 
In this case, while the team expressed communication and scheduling concerns, accountability concerns outstripped both by a wide margin. Team members were preoccupied with fostering accountability in their teammates while avoiding their own accountability. This finding is interesting because the previous data analysis covering 34 students across three semesters confirmed student concerns with communication effectiveness exceeded all other concerns. In this case Jarvenpaa, Knoll, and Leidner's (1998) research on virtual team trust offers a possible explanation. They compared high performing and low performing virtual teams in explaining the concept of "swift trust," a type of trust that occurs when team members come together on virtual teams that have not met in person. In such situations team members tend to focus on teammates' skills and experiences to assess their abilities and they expect their teammates to deliver. Swift trust is fragile, so if these virtual team members conclude their teammates are not meeting commitments, trust quickly degrades. Since the team under study exhibited constant rancor and an inability to meet their commitments it appears their swift trust evaporated. It may be justifiable to conclude their difficulty achieving reasonable levels of teamwork drove their emphasis on accountability, implying different contexts drive differing team concerns. These findings do not call Lohle and Terrell's (2016) theoretical model into question but they appear to indicate various constructs will receive increased or decreased emphasis in different situations. It would be interesting to explore additional cases to assess this variability of emphasis and further reinforce or extend the theoretical model's design.

\section{Two Concerns Emerge}

This case study also highlights two concerns. First, the weekly status reports' positive tone contradicted feedback provided in other communications. Second, even with constant escalation both team and instructor invested considerable time and scrambled at the end of the project to submit a viable work product. Unless students actively notify their instructor and the instructor aggressively responds it is difficult to assess student contribution on team projects. This situation is exacerbated when a virtual team project is delivered in an online course because communications are sent electronically; the instructor and students are geographically distributed and responsiveness tends to degrade.

In this case the instructor aggressively solicited student feedback and facilitated closure. This student team was one of several the instructor administered during this short semester in addition to an extended suite of assignments so the constant escalation and demand became exhausting. It is reasonable to ask whether there is a more effective way to ensure a virtual student team delivers than relying on constant instructor vigilance.

\section{Conclusion}

\section{Additional Tests for the Theoretical Model}

Assessing Lohle and Terrell's (2016) theoretical model's design constructs in light of this case's findings is interesting because the tenacious lack of accountability exhibited by the team under study adversely impacted team member trust and their concerns about accountability overshadowed concerns about effective communication and scheduling. While this finding does not necessarily call the theoretical model into question, it does suggest additional study is warranted to ascertain whether variations in the lived experiences of different teams indicates the 
need for model refinements or whether they simply imply different aspects of the model will receive more or less emphasis depending upon the situation. As Eisenhardt (1989) suggested, comparison with additional case studies is advisable to detect patterns that will facilitate a deeper understanding of the theoretical model.

\section{Recommendations and Opportunities for Additional Research}

When designing an online course it is important to offer multiple communication vehicles. In this case if the instructor was exposed only to the project status reports, intervention to facilitate closure might not have occurred because these reports engendered a false sense of confidence. As previously mentioned, the instructor communicated the following advice to the class:

- Teams that do not address communication issues will not deliver effectively

- The weekly status report should be used to heighten the impact of underperforming teammates

- Teams should invite the instructor to join team meetings if additional support is required.

Prior to this case study the instructor concluded the mere "threat" presented in the second and third bullets fostered productivity. This case appears to undermine this conclusion. Here the team provided a false sense of security in their weekly status reports and one of them was relentlessly positive. This provides an opportunity for additional research.

Peer reviews may serve as an antidote for the exhaustive instructor facilitation required in this case. Logically, such reviews should foster collaboration because team members hold each other accountable. Unfortunately, the facts of this case undermine this. Throughout their time together this team escalated constantly in what amounted to an evolving peer review. Moreover, they ratified a final grade allocation for each team member's contribution that also served as another peer review. These makeshift peer review mechanisms never motivated these students to become accountable to each other or to provide quality work so it is reasonable to conclude peer reviews would not have had the desired effect. This also provides an opportunity for further research.

Communication effectiveness in online courses is hindered by an inability to converse with teammates in person and to view body language. While this online course's personal reflections and synchronous meetings could be considered a substitute, it would also be instructive to evaluate the impact that the lack of social presence in virtual projects conducted during online courses has on student team success (Owens, Davis, Murphy, Khazanchi \& Zigurs, 2009).

\section{References}

Creswell, J. W. (2007). Qualitative inquiry and research design: Choosing among five approaches (2nd ed.). Thousand Oaks, CA: Sage Publications, Inc.

Davenport, T. (2015, June 24). Whatever happened to knowledge management? The Wall Street Journal. Retrieved July 12, 2016, from http://blogs.wsj.com/cio/2015/06/24/whateverhappened-to-knowledge-management/ 
Eisenhardt, K. (1989). Building theories from case study research. The Academy of Management Review, 14(4), 532-550. Retrieved from http://www.jstor.org/stable/258557

Gersick, C. J. G. (1988). Time and transition in work teams: Toward a new model of group development. Academy of Management Journal, 31(1), 9-41.

Glaser, B. G., \& Strauss, A. L. (1967). The discovery of grounded theory: Strategies for qualitative research. Chicago, IL: Aldine Publishing Company.

Jarvenpaa, S. L., Knoll, K., \& Leidner, D. E. (1998). Is anybody out there? Antecedents of trust in global virtual teams. Journal of Management Information Systems, 14(4), 29-64.

Lee, J. (2015). Why death of chief knowledge officers is a good thing. The APQC Blog. Retrieved 7/12/2016 from https://www.apqc.org/blog/why-death-chief-knowledge-officersgood-thing

Lohle, M., \& Terrell, S. (2016). Knowledge management using student feedback: A study of online students' lived experience on virtual teams. Issues in Information Systems, 17(4), 260 -265 .

Nonaka, I. (1994). A dynamic theory of organizational knowledge creation. Organization Science, 5(1), 14-37. Retrieved from http://www.jstor.org/stable/2635068

Owens, D., Davis, A., Murphy, J. D., Khazanchi, D., \& Zigurs, I. (2009). Real-world opportunities for virtual project management. IT Pro, 34-41.

Skyrme, D. (2011). The evolution of knowledge management. David Skyrme Associates. Retrieved 7/12/2016 from http://www.skyrme.com/kmbasics/evolution.htm

\section{Authors' Biographies}

Dr. Mike Lohle Dr. Mike Lohle is a Senior Lecturer with the University of Bridgeport's Ernest C. Trefz School of Business. A certified Project Management Professional (PMP), Mike spent twenty-six years in the financial services, insurance, information technology services, pharmaceutical and consumer product industries before transitioning to academia. He is experienced with all aspects of information technology and his specialty is delivering large business intelligence and analytics solutions for major corporations. Dr. Lohle has consulted for and been employed by General Electric, American Skandia, Keane, Condor Technology Solutions, PartnerRe, Avon, Gartner, Travelers, Anthem and Morgan Stanley. Since 2012, Dr. Lohle has also served as a Ph.D. dissertation advisor for Nova Southeastern University's College of Engineering and Computing and he also serves on dissertation committees for Ph.D. Students in UB's Technology Management program. Any correspondence can be made to the following: Phone: 203-770-3854; E-mail: mlohle @ bridgeport.edu. 
Dr. Steve Terrell teaches quantitative and qualitative research methodology and statistics at Nova Southeastern University's Fischler College of Education and the College of Computing and Engineering. He has graduate degrees in higher education, counseling and business and is an active member of the American Counseling Association, the American Psychological Association and the American Educational Research Association where he serves as chair of the Online Teaching and Learning Special Interest Group. Dr. Terrell serves on the editorial board of several national and international journals and is the author of Writing a Proposal for Your Dissertation: Guidelines and Examples and Statistics Translated: A Step-by-Step Guide to Analyzing and Interpreting Data as well as over 120 journal articles, book chapters, conference papers and presentations. Any correspondence can be made to the following: Phone: 954-262-2084; E-mail: terrell@nova.edu. 